\title{
Effect of the absence of the CcpA gene on growth, metabolic production, and stress tolerance in Lactobacillus delbrueckii ssp. bulgaricus
}

\author{
C. Li, J. W. Sun, G. F. Zhang, and L. B. Liu ${ }^{1}$ \\ Key Laboratory of Dairy Science, Ministry of Education, College of Food Science, Northeast Agricultural University, Harbin, China 150030
}

\begin{abstract}
The catabolite control protein A (CcpA) is a kind of multi-effect regulatory protein. In the study, the effect of the inactivation of CcpA and aerobic conditions on the growth, metabolic production, and stress tolerance to heat, oxidative, and cold stresses in Lactobacillus delbrueckii ssp. bulgaricus was investigated. Results showed that inactivation of CcpA distinctly hindered growth. Total lactic acid concentration was significantly lower in aerobiosis for both strains and was lower for the mutant strain than L. bulgaricus. Acetic acid production from the mutant strain was higher than $L$. bulgaricus in aerobiosis compared with anaerobiosis. Enzyme activities, lactate dehydrogenase (LDH), phosphate fructose kinase (PFK), pyruvate kinase (PK), and pyruvic dehydrogenase $(\mathrm{PDH})$, were significantly lower in the mutant strain than L. bulgaricus. The diameters of inhibition zone were $13.59 \pm 0.02 \mathrm{~mm}$ and $9.76 \pm 0.02 \mathrm{~mm}$ for L. bulgaricus in anaerobiosis and aerobiosis, respectively; and $8.12 \pm 0.02 \mathrm{~mm}$ and 7.38 $\pm 0.02 \mathrm{~mm}$ for the mutant in anaerobiosis and aerobiosis, respectively. For both strains, cells grown under aerobic environment possess more stress tolerance. This is the first study in which the CcpA-negative mutant of $L$. bulgaricus is constructed and the effect of aerobic growth on stress tolerance of $L$. bulgaricus is evaluated. Although aerobic cultivation does not significantly improve growth, it does improve stress tolerance.
\end{abstract}

Key words: Lactobacillus bulgaricus, CcpA deletion, mutant, enzyme, stress resistance

\section{INTRODUCTION}

Carbon catabolite repression $(\mathbf{C C R})$ is defined as a phenomenon that microorganisms preferentially use a rapidly metabolizable carbon source, along with inhibition of some gene expression and enzyme activities related to catabolism of nonpreferred carbon resources

Received August 27, 2015.

Accepted September 28, 2015.

${ }^{1}$ Corresponding author: liboliu@126.com
(Magasanik, 1961). In low-GC gram-positive bacteria, the key regulator for exerting CCR is CcpA, which is a pleiotropic regulator involved in various physiological processes in addition to CCR, including central carbon and nitrogen metabolism, biofilm formation, and toxin gene expression.

The CcpA is a DNA-binding protein belonging to the Lacl/GalR family of transcriptional regulators. The CcpA, linked to the serylphosphorylated form of phosphocarrier protein HPr (HPr-Ser-P), binds to a catabolite response element (cre) that is commonly located in the proximity of promoters, thereby either repressing or enhancing the transcription of downstream operons (Weickert and Adhya, 1992). The cre-like elements are identified in each of these DNA fragments. Catabolite control of PepQ is demonstrated in Lactobacillus delbrueckii ssp. lactis (Schick et al., 1999). Lactobacillus bulgaricus PepR1 biosynthesis is not constitutive like those of several bacteria but is autoregulated and depends on the glucose concentration of the culture medium (Morel et al., 2001).

The CcpA protein has a key role in the regulation of the aerobic metabolism in Lactococcus lactis (Gaudu et al., 2003; Lopez de Felipe and Gaudu, 2009) and in Lactobacillus plantarum (Lorquet et al., 2004; Goffin et al., 2006). Moreover, CcpA is also involved in stress response mechanisms in L. plantarum by exerting positive control on the DnaK and GroESL operons (Muscariello et al., 2001; Castaldo et al., 2006) and the regulation of aerobic metabolism in both $L$. plantarum (Lorquet et al., 2004) and L. lactis (Gaudu et al., 2003; Lopez de Felipe and Gaudu, 2009), and it regulates the expression of the class I heat shock response operons in L. plantarum (Castaldo et al., 2006). Aerobic growth under respiration conditions was able to improve the tolerance of several technologically relevant stresses (heat, oxidative stress, and starvation) in lactic acid bacteria (LAB; Lechardeur et al., 2011) and then CcpA can perform the role of stress response regulation and aerobic metabolism.

The CcpA directly or indirectly controls the transcription of a large number of genes (>300 in Bacillus subtilis, $\geq 237$ in L. lactis) involved in both energy and 
nitrogen metabolism. The role of CcpA in metabolism regulation has been studied in several LAB, including $L$. lactis (Zomer et al., 2007; Lopez de Felipe and Gaudu, 2009), Lactobacillus casei (Gosalbes et al., 1999), Lactobacillus pentosus (Mahr et al., 2000), and L. plantarum (Castaldo et al., 2006; Rud et al., 2011).

In this study, the CcpA gene knockout mutant of $L$. bulgaricus was constructed using homologous recombination technology to study the effect of the inactivation of CcpA and aerobic growth on metabolite production, enzyme activities, and stress tolerance.

\section{MATERIALS AND METHODS}

\section{Materials}

Escherichia coli DH5a was used as the host for cloning. Escherichia coli strains were cultivated aerobically at $37^{\circ} \mathrm{C}$ in Luria-Bertani medium ( $1 \%$ tryptone, $0.5 \%$ yeast extract, $0.5 \% \mathrm{NaCl}$ ). Lactobacillus bulgaricus ATCC11842 strain was purchased from American Type Culture Collection (Manassas, VA). Its mutant $(\Delta c c p A$ tet) was obtained in this experiment. Lactobacillus bulgaricus and its mutant were cultivated at $37^{\circ} \mathrm{C}$, under aerobic or anaerobic conditions, in de Man, Rogosa, Sharpe (MRS) broth. The plasmid pBR322 harboring the gene for the tetracycline resistance (Tet) gene, pBackZero-T Vector, DNA polymerase and restriction enzyme EcoRI and PstI, $\mathrm{T}_{4}$ DNA ligase, and agarose gel DNA purification kit were purchased from TaKaRa Biotechnology Co., Ltd. (Dalian, China). The DNA sequencing and primer synthesis were performed by Shanghai Sangon Biological Engineering Technology and Services Co. Ltd. (Shanghai, China). The PCR primers were designed using the Primer Premier software program (version 6; Premier Biosoft, Palo Alto, CA).

\section{Cloning of the CcpA Gene}

The whole CcpA gene (NCBI accession number 4084515) was amplified by PCR using L. bulgaricus genomic DNA as a template. CcpA-F: 5'-TTTAAGGCTGGAGTCAGAAGCGTAG-3', CcpA-R: 5'-TTTAAATCGTGATGGCGTCATAGTG-3'. The PCR conditions consisted of $2.5 \mu \mathrm{L}(50 \mathrm{ng} / \mu \mathrm{L})$ of DNA and $1 \mu \mathrm{L}$ of each primer $(10 \mathrm{p} M)$ in a $10-\mu \mathrm{L} 5 \times$ reaction buffer, $4 \mu \mathrm{L}$ of $10 \mathrm{~m} M$ dNTP mixture, and $0.5 \mu \mathrm{L}$ of 5 U PrimeSTAR HS DNA polymerase in a final volume of $50 \mu \mathrm{L}$ in a PCR machine (GeneAmp PCR System 9700, Applied Biosystems Co., Foster City, CA). The PCR was initiated with an incubation step at $94^{\circ} \mathrm{C}$, $2 \mathrm{~min}$, followed by 35 cycles of $98^{\circ} \mathrm{C}, 10 \mathrm{~s} ; 55^{\circ} \mathrm{C}, 15 \mathrm{~s}$; $72^{\circ} \mathrm{C}, 3 \mathrm{~min}$, with a final extension step at $72^{\circ} \mathrm{C}, 10 \mathrm{~min}$.
The amplified DNA product was electrophoresed on a $1 \%$ (wt/vol) agarose gel. The length of $C c p A$ gene was $2.5 \mathrm{~kb}$; CcpA sequencing was performed by Shanghai Sangon Biological Engineering Technology and Services Co., Ltd.. The PCR product was purified using a PCR purification kit from Qiagen (Beijing, China) according to the manufacturer's instructions, and was then cloned into pBackZero-T Vector, which was used for constructing the intermediate vector pBackZero-CcpA. The construct was transformed into $E$. coli DH5a competent cells, which were then used to propagate the plasmid construct. The transformants were selected on Luria-Bertani plates containing $100 \mu \mathrm{g} / \mathrm{mL}$ of ampicillin, $0.5 \mathrm{~m} M$ isopropyl $\beta$-D-1-thiogalactopyranoside, and $80 \mu \mathrm{g} / \mathrm{mL}$ of X-Gal. The white colonies were selected and a mini-scale isolation of the plasmid DNA was used to prepare the recombinant plasmid. pBackZero- $C c p A$ was digested with EcoRI and PstI restriction enzyme, generating 2 fragments of 5.1 and $0.7 \mathrm{~kb}$.

\section{Cloning of tet Gene}

For the selection of knockout colonies, the tetracycline resistance gene (National Center for Biotechnology Information accession number J01749.1) was used for the transformant selection. Briefly, the Tet gene was amplified by PCR with the $5^{\prime}$-primer containing an EcoRI restriction site (Tet-F: 5'-CCGGAATTCTTCTCATGTTTGACAGCTTATC ATC-3') and 5'-primer containing a $P s t \mathrm{I}$ restriction site (Tet-R: 5'-AACTGCAG TAATAGATATGTTCTGCCAAGGGTT-3'). The PCR conditions were the same as those for the CcpA gene. The PCR was initiated with an incubation step at $94^{\circ} \mathrm{C}, 2 \mathrm{~min}$, followed by 30 cycles of $98^{\circ} \mathrm{C}, 10 \mathrm{~s} ; 55^{\circ} \mathrm{C}$, $15 \mathrm{~s} ; 72^{\circ} \mathrm{C}, 1.5 \mathrm{~min}$, with a final extension step at $72^{\circ} \mathrm{C}$, $10 \mathrm{~min}$. The following cloning procedures were the same as that of CcpA gene. The length of the Tet gene was $1.4 \mathrm{~kb}$. The Tet sequencing was performed by Shanghai Sangon Biological Engineering Technology and Services Co., Ltd.. The PCR product was cloned into pBackZero, generating pBackZero-Tet. pBackZero-Tet was digested with EcoRI and PstI restriction enzyme generating 2 fragments of 3.2 and $1.4 \mathrm{~kb}$. Details on CcpA, mutation, and tet sequencing are in the Supplemental Data (http://dx.doi.org/10.3168/jds.2015-10321).

\section{Preparation of an Insert for Homologous Recombination}

Two constructs (pBackZero-CcpA and pBackZeroTet) were digested with 2 restriction enzymes, EcoRI and PstI, and the Tet gene was inserted into the EcoRI + PstI-site of pBackZero-CcpA (0.6-kb fragment of CcpA gene was exchanged with 1.4-kb Tet gene), 
generating pCT. A linear DNA fragment (CcpA-TetCcpA: $3.3 \mathrm{~kb})$ was produced by PCR amplification of $\mathrm{pCT}$ and used as an insert $(50 \mathrm{ng} / \mu \mathrm{L})$ for homologous recombination. The insert sequencing were performed by Shanghai Sangon Biological Engineering Technology and Services Co., Ltd..

\section{Gene Disruption by Homologous Recombination}

Five milliliters of the $L$. bulgaricus stock culture stored at $-80^{\circ} \mathrm{C}$ was inoculated into $30 \mathrm{~mL}$ of MRS broth containing a final concentration of $1 \%$ glycine from Solarbio (Beijing, China). Cells were cultivated to an optical density at $600 \mathrm{~nm}\left(\mathrm{OD}_{600}\right)$ of approximately 0.3 , chilled on ice for $15 \mathrm{~min}$, centrifuged at $7,000 \times g$ for $10 \mathrm{~min}$ at $4^{\circ} \mathrm{C}$. The supernatant was removed and the pellet was concentrated and washed 3 times with ice-cold sterile distilled water. Wash water was removed and cells were resuspended in an equal volume of cold sterile PEG-8000 (30\%, wt/vol) and served as a source of competent cells. Eighty microliters of the electrocompetent cells were transformed with $4 \mu \mathrm{L}$ (50 ng) of insert DNA (CcpA-Tet-CcpA) and $1 \mu \mathrm{L}(50 \mathrm{ng})$ of vector $\mathrm{pCT}$ by using an electroporation system (Gene Pulser Xcell, Bio-Rad Co., Hercules, CA) at $2.3 \mathrm{kV}$, $200 \Omega$, and $25 \mu \mathrm{F}$. Knockout mutants were selected on MRS plates containing $10 \mu \mathrm{g} / \mathrm{mL}$ of tetracyclines at $37^{\circ} \mathrm{C}, 72 \mathrm{~h}$.

\section{PCR Verification}

The structure of mutant was analyzed by PCR. Genomic DNA from a mutant colony was prepared (50 $\mathrm{ng} / \mu \mathrm{L})$ and used as a template. Primers CcpA-F and Tet-F were used for PCR 1, and CcpA-R and Tet-R were used for PCR 2.

\section{Measure of the Strain Phenotype}

Both strains were observed based on their colony morphology in MRS agar medium without tetracycline, including the size of the colony, color, and edge appearance. Growth of both strains were observed in MRS agar medium with $10 \mu \mathrm{g} / \mathrm{mL}$ of tetracycline.

\section{Growth, Chemical, and Biochemical Analyses}

The growth of cell was measured by spectrophotometry. One hundred microliters of culture containing about $10^{8} \mathrm{cfu} / \mathrm{mL}$ was transferred to $5 \mathrm{~mL}$ of MRS broth and cultivated at $37^{\circ} \mathrm{C}$ under aerobic or anaerobic conditions. The absorbance of the culture was monitored at $600 \mathrm{~nm}$ in a spectrophotometer (DU-800; Beckman Coulter Co., Fullerton, CA) every 2 h. The growth curve was drawn with culture time as abscissa and $\mathrm{OD}_{600}$ as ordinate.

High-performance liquid chromatography was used for the measurement of glucose, DL-lactic acid, and acetate concentrations in culture supernatants (Sánchez et al., 2004). Studies were performed with buffered cell suspensions, which greatly facilitate product analysis. Five milliliters of L. bulgaricus cultures was collected in the stationary growth phase by centrifugation at 10,000 $\times g$ for $10 \mathrm{~min}$ at $4^{\circ} \mathrm{C}$. The pellet was washed twice with $33 \mathrm{~m} M$ potassium phosphate buffer, $\mathrm{pH} 7.0$ (PB7), and resuspended in $5 \mathrm{~mL}$ of $33 \mathrm{mM}$ potassium phosphate buffer, pH 5.6, containing $25 \mathrm{~m} M$ glucose. The suspension was incubated with constant mild stirring for $4 \mathrm{~h}$. Cells were removed from the suspension by centrifugation at $7,311 \times g$ for $10 \mathrm{~min}$ and the supernatant was analyzed by HPLC to quantify the glucose, DL-lactic acid, and acetic acid levels. The Alliance HPLC 2695 series (Waters, Palo, Alto, CA) was used. Ten microliters of samples was separated at a flow rate of $0.5 \mathrm{~mL} /$ min at $65^{\circ} \mathrm{C}$ on a $300 \times 7.8 \mathrm{~mm} \mathrm{HPX}-87 \mathrm{H}$ Aminex ionexchange column protected by a cation Ht Microguard cartridge (Bio-Rad Co.), using $5 \mathrm{~m} M$ sulfuric acid as the mobile phase. The Waters 2487 Dual $\lambda$ Absorbance detector was used for the quantification of organic acids at $210 \mathrm{~nm}$. Glucose was analyzed using a Waters 2414 Differential Refractometer detector.

\section{Enzyme Activity}

The BCA protein assay kit (Beyotime Institute of Biotechnology, Shanghai, China) was used to determine protein concentrations. The LDH kit was used to determine lactate dehydrogenase (LDH). The PFK kit was used to determine phosphate fructose kinase (PFK). The PK kit was used to determine pyruvate kinase (PK). The PDH kit was used to determine pyruvic dehydrogenase (PDH). These enzyme kits were purchased from Comin Biotechnology Co., Ltd. (Suzhou, China).

\section{Stress Tolerance}

The tolerance to heat, oxidative, and cold stress was evaluated on stationary phase cells $(24 \mathrm{~h})$, which were recovered by centrifugation at $10,000 \times g$ for 5 min at $4^{\circ} \mathrm{C}$ and washed twice in $20 \mathrm{mmol}$ per liter PB7 and resuspended in PB7 to $600 \mathrm{~nm}$ of 1.0. For heat stress, standardized cells were rapidly added to pre-warmed $\left(55^{\circ} \mathrm{C}\right) \mathrm{PB} 7$ in tubes in a circulation water bath (van Kranenburg et al., 1997). Survival was measured by counting the colony-forming units per milliliter $\left(37^{\circ} \mathrm{C}\right.$, $48 \mathrm{~h}$ ) in MRS agar at 0, 10, 20, 30, and $40 \mathrm{~min}$. Oxidative stress tolerance was tested by spotting $2 \mu \mathrm{L}$ of $1.0 \%$ 
$\mathrm{H}_{2} \mathrm{O}_{2}$ on the top layer $(7 \mathrm{~mL})$ of MRS agar (containing $1.5 \% \mathrm{wt} / \mathrm{wt}$ bacteriological agar) inoculated with 100 $\mu \mathrm{L}$ of standardized cell suspension, on a $10-\mathrm{mL}$ bottom layer of sterile MRS agar. The area of the inhibition zone was measured with a caliper after incubation at $37^{\circ} \mathrm{C}, 48 \mathrm{~h}$. Tolerance to cold storage was evaluated by storing standardized cell suspensions at $4^{\circ} \mathrm{C}$ and survival was measured by counting the colony-forming units per milliliter in MRS agar at 0, 5, 10, 15, and 20 d.

\section{Statistical Methods}

Excel 2003 software (Microsoft Corp., Redmond, WA) was used for statistical analysis, and the test was repeated 3 times. The results were the average \pm standard deviation from 3 independent tests.

\section{RESULTS}

\section{PCR Verification of Genomic DNA from a Mutant Colony}

The sequencing results were tested by using BLAST and compared with the corresponding subtypes. The results showed that similarity degrees of CcpA, Tet, and CcpA mutation sequence were $99 \%$. The expected sizes and targets of $2 \mathrm{PCR}$ are represented in Figure $1 \mathrm{~A}$. In the $2 \mathrm{PCR}$ for the verification of mutated genomic structure, $2(2.0$ and $2.7 \mathrm{~kb})$ PCR products were produced as shown in Figure 1B, indicating the correct structure was generated.

\section{The Strain Phenotype}

Lactobacillus bulgaricus and its mutant were cultivated at $37^{\circ} \mathrm{C}$ in MRS agar medium without tetracycline. The CcpA gene deletion mutant and wild type strains have no obvious phenotypic difference on colony morphology, colonies were white, translucent, with luster and a jagged edge, and the colony was shaped like a snowflake. The colony morphology is shown in Figure 2 (A: wild type; B: mutant).

Lactobacillus bulgaricus and its mutant were cultivated at $37^{\circ} \mathrm{C}$ in MRS agar medium with $10 \mu \mathrm{g} / \mathrm{mL}$ of tetracycline. The wild type strain could not grow, whereas the growth condition of CcpA gene deletion mutant was normal.

\section{Growth and Metabolite Production}

The growth in aerobiosis and anaerobiosis of $L$. bulgaricus and of its mutant was compared. The growth curve is shown in Figure 3, whereas kinetic parameters

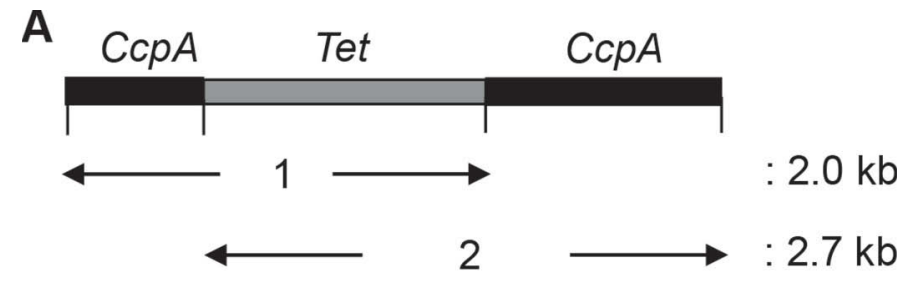

B

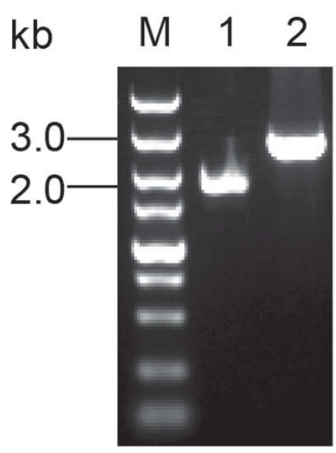

Figure 1. The results of the PCR amplification of genomic DNA from a mutant colony. (A) Diagram of PCR verification for genomic structure. The expected sizes and targets of 2 PCR (1-2) were indicated. (B) The result of the PCR verification. One $2.0 \mathrm{~kb}$ (PCR 1: lane 1) and one $2.7 \mathrm{~kb}$ (PCR 2: lane 2) of PCR products were produced. Catabolite control protein A (CcpA).

and metabolite concentrations are reported in Table 1. The mean \pm standard error are for 3 replicate fermentations.

The growth curve was lower in anaerobiosis for both strains after $12 \mathrm{~h}$ and was lower for the mutant strain than L. bulgaricus. Inactivation of CcpA severely impaired growth. Estimated maximal growth rate $(\boldsymbol{\mu} \max )$ values are shown in Table 1 , indicating differences between $\mu$ max of $L$. bulgaricus and its mutant were significant $(P<0.05)$. Total lactic acid concentration was significantly lower in aerobiosis for both

A

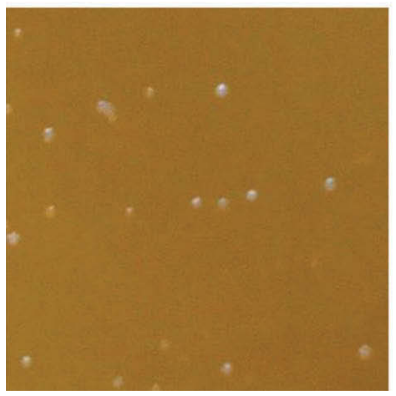

Figure 2. Colony morphology for (A) the wild type Lactobacillus bulgaricus and (B) the mutant. Color version available online. 
Table 1. Kinetic parameters $(\mu=$ growth rate) and metabolite concentrations (means \pm SD)

\begin{tabular}{|c|c|c|c|c|c|}
\hline Strain & $\begin{array}{l}\text { Culture } \\
\text { condition }\end{array}$ & $\mu(1 / h)$ & Glucose (g/L) & DL-Lactic acid (g/L) & Acetic acid $(\mathrm{g} / \mathrm{L})$ \\
\hline \multirow[t]{2}{*}{ Wild type } & $\mathrm{N}_{2}$ & $0.583 \pm 0.011^{\mathrm{b}}$ & $2.451 \pm 0.033^{\mathrm{c}}$ & $17.508 \pm 0.027^{\mathrm{a}}$ & $0.965 \pm 0.038^{\mathrm{c}}$ \\
\hline & Air & $0.645 \pm 0.005^{\mathrm{a}}$ & $1.508 \pm 0.012^{\mathrm{d}}$ & $14.126 \pm 0.100^{\mathrm{c}}$ & $4.164 \pm 0.048^{\mathrm{b}}$ \\
\hline Mutant & Air & $0.467 \pm 0.007^{\mathrm{c}}$ & $2.875 \pm 0.027^{\mathrm{b}}$ & $9.584 \pm 0.015^{\mathrm{d}}$ & $6.246 \pm 0.035^{\mathrm{a}}$ \\
\hline
\end{tabular}

${ }^{\mathrm{a}-\mathrm{d}}$ Values in each column with different superscripts show significant differences between the group and other groups $(P<0.05)$.

strains after $24 \mathrm{~h}$ (stationary phase) and was lower for the mutant strain than $L$. bulgaricus. The yield of lactic acid was always lower than that predicted for homolactic fermentation (2 mol lactic acid per mol glucose). Acetic acid production was higher in aerobiosis than anaerobiosis and for the mutant strain other than $L$. bulgaricus.

\section{Enzyme Activity}

The enzyme activities in aerobiosis and anaerobiosis of $L$. bulgaricus and its mutant were compared. The protein concentrations and key glycolytic enzymes are reported in Table 2. Protein concentrations are shown in Table 2, indicating that differences between $L$. bulgaricus and its mutant were significant $(P<0.05)$. Enzyme activities (LDH, PK, PFK, PDH) were significantly lower in the mutant strain than L. bulgaricus. For L. bulgaricus, enzyme activities (LDH, PK, PFK) were significantly lower in aerobiosis than anaerobiosis, but it was not significant for the mutant strain. For $L$. bulgaricus and its mutant strain, enzyme activity (PDH) was not significant in_either aerobiosis or anaerobiosis.

\section{Stress Tolerance}

The tolerance of stationary phase cells to heat, oxidative, and cold stresses was assayed. The curve of heat inactivation is shown in Figure 4. Inactivation of CcpA impaired heat tolerance. For both strains, cells grown in aerobiosis were more tolerant of heat compared with anaerobiosis $(P<0.05)$.

Oxidative stress tolerance was assayed using a spoton-lawn method (Zotta et al., 2012). The diameters of the inhibition zone caused by $2 \mu \mathrm{L}$ of a $1.0 \% \mathrm{H}_{2} \mathrm{O}_{2}$ solution were measured with a vernier caliper. The diameters of the inhibition zone were $13.59 \pm 0.02 \mathrm{~mm}$ and $9.76 \pm 0.02 \mathrm{~mm}$ for L. bulgaricus in anaerobiosis and aerobiosis, respectively; and $8.12 \pm 0.02 \mathrm{~mm}$ and $7.38 \pm 0.02 \mathrm{~mm}$ for the mutant in anaerobiosis and aerobiosis, respectively.

The above results showed that the mutant was more tolerant than the wild type for oxidative stress, regard- less of whether it was grown in aerobiosis or anaerobiosis. Moreover, no matter which strain, aerobically grown cells were significantly more tolerant.

The survival of stationary cells after cold storage in potassium phosphate buffer ( $\mathrm{pH} 7$ ) was evaluated. The results of plate counts on MRS agar for stationary phase cells are shown in Figure 5. Cells grown in aerobiosis were significantly more resistant. The difference in survival for aerobic grown cells was negligible for both strains, whereas L. bulgaricus cells grown in anaerobiosis were significantly more tolerant than mutant cells grown in the same conditions.

\section{DISCUSSION}

Inactivation of CcpA, and to some extent incubation in aerobiosis, significantly affected growth and its metabolites in L. bulgaricus. The results were in agreement with what has been found for other microorganisms (Titgemeyer and Hillen, 2002; Esteban et al., 2004), although the growth differences of some species have not been observed in CcpA-disrupted mutants (Asanuma et al., 2004). Aeration did not significantly affect the growth rate in spite of increasing ATP production, which would be expected in the mutant grown

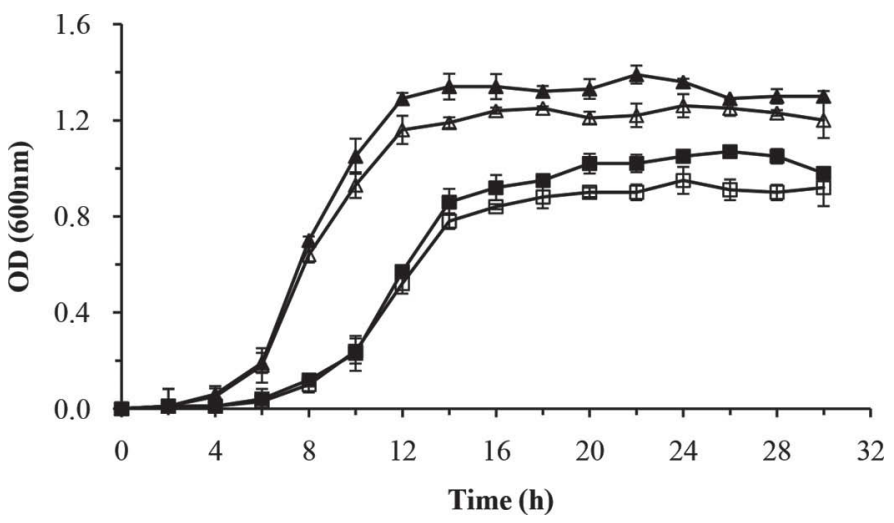

Figure 3. Growth curve of representative fermentations measured as optical density at $600 \mathrm{~nm}\left(\mathrm{OD}_{600}\right)$. Lactobacillus bulgaricus $(\Delta, \mathbf{\Lambda})$ and its mutant $(\square, \boldsymbol{\square})$ were controlled at temperature $\left(37^{\circ} \mathrm{C}\right)$ in de Man, Rogosa, Sharpe broth with anaerobiosis (open symbols) or aerobiosis (closed symbols). Error bars indicate SD. 
Table 2. Protein concentration and enzyme activity (means $\pm \mathrm{SD})^{1}$

\begin{tabular}{|c|c|c|c|c|c|c|}
\hline Strain & $\begin{array}{l}\text { Culture } \\
\text { condition }\end{array}$ & Protein $(\mathrm{mg} / \mathrm{mL})$ & LDH (U/mg) & PFK (U/mg) & $\mathrm{PK}(\mathrm{U} / \mathrm{mg})$ & $\mathrm{PDH}(\mathrm{U} / \mathrm{mg})$ \\
\hline \multirow[t]{2}{*}{ Wild type } & $\mathrm{N}_{2}$ & $2.255 \pm 0.089^{\mathrm{b}}$ & $50.980 \pm 0.502^{\mathrm{a}}$ & $50.089 \pm 0.586^{\mathrm{a}}$ & $90.028 \pm 0.717^{\mathrm{a}}$ & $35.906 \pm 0.382^{\mathrm{a}}$ \\
\hline & Air & $2.808 \pm 0.079^{\mathrm{a}}$ & $23.316 \pm 0.542^{\mathrm{b}}$ & $28.977 \pm 0.797^{\mathrm{b}}$ & $37.792 \pm 0.310^{\mathrm{b}}$ & $34.103 \pm 0.336^{\mathrm{a}}$ \\
\hline Mutant & Air & $0.820 \pm 0.066^{\mathrm{c}}$ & $14.747 \pm 0.400^{c}$ & $10.757 \pm 0.586^{\mathrm{c}}$ & $26.767 \pm 0.594^{\mathrm{c}}$ & $17.540 \pm 0.079^{\mathrm{b}}$ \\
\hline
\end{tabular}

${ }^{\mathrm{a}-\mathrm{c}}$ Values in each column with different superscripts show significant differences between the group and other groups $(P<0.05)$.

${ }^{1} \mathrm{LDH}=$ lactate dehydrogenase; PFK = phosphate fructose kinase; PK = pyruvate kinase; PDH = pyruvic dehydrogenase.

in aerobiosis because of pyruvate oxidase and acetate kinase activity (Quatravaux et al., 2006). On the other hand, aeration did not reduce the growth rate in the exponential phase (Murphy and Condon, 1984b). The expression of enzymes (LDH, PFK, PK) was reduced in the mutant compared with the wild type, in agreement with what has been found for L. lactis (Ramos et al., 2004), and this might account for the reduced growth rate of the mutant in agreement with what has been found for other species (Luesink et al., 1998; Ludwig et al., 2001). No data are available to show that CcpA might be a key protein controlling $\mathrm{PDH}$ metabolism in the citric acid cycle. The expression of enzymes (PDH) was reduced in the mutant compared with the wild type, which might be caused by the reduced growth rate of the mutant.

However, the largest differences between the 2 strains were found in aerobiosis. The yield of lactic acid at 24 $\mathrm{h}$ was lower than in anaerobiosis, whereas more acetic acid was produced, as expected by the role of CcpA in the control of the expression of Pox genes (Lorquet et al., 2004; Goffin et al., 2006), which is confirmed by the increased and anticipated acetic acid production in the mutant. Oxygen and CCR play an important role in

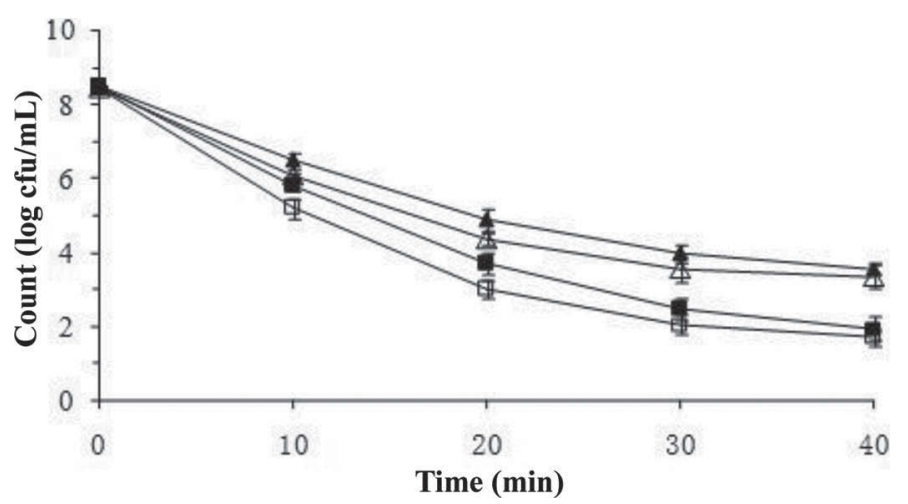

Figure 4 . The curve of stationary phase cells to heat. Lactobacillus bulgaricus $(\Delta, \mathbf{\Lambda})$ and its mutant $(\square, \mathbf{\square})$ were controlled at temperature $\left(37^{\circ} \mathrm{C}\right)$ in de Man, Rogosa, Sharpe broth with no air (open symbols) or air sparging (closed symbols) following exposure to $55^{\circ} \mathrm{C}$ in 20 $\mathrm{mmol} / \mathrm{L}$ potassium phosphate buffer, $\mathrm{pH}$ 7.0. Error bars indicate SD. the presence of Pox, Nox, and Npr genes (Murphy and Condon, 1984a).

The higher stress tolerance of stationary phase cells is in agreement with the literature for L. lactis (Esteban et al., 2004) and is probably due to a generalized stress response. Although aeration significantly affected growth and stress tolerance for L. plantarum (Zotta et al., 2012), no data are available in the literature on the effect of aerobic growth of L. bulgaricus on stress tolerance. The increasing expression of some heat-stressrelated proteins (GrpE, ClpL) of L. bulgaricus grown in aerobiosis is the key cause of increasing heat stress resistance and can also be one of the indirect causes of increasing tolerance to oxidative stress, which may improve recovery of sub-lethally damaged cells (Zotta et al., 2012). However, growth in aerobiosis can promote the formation of an electron transport chain, which has been found to significantly increase tolerance to oxidative stress (Gaudu et al., 2002).

However, the mutant strain seemed to be more responsive to the oxidative environment, which implied that a larger number of proteins was involved in the adaptation mechanism (Mazzeo et al., 2012). Hydrogen peroxide has been found to affect the transcription of a

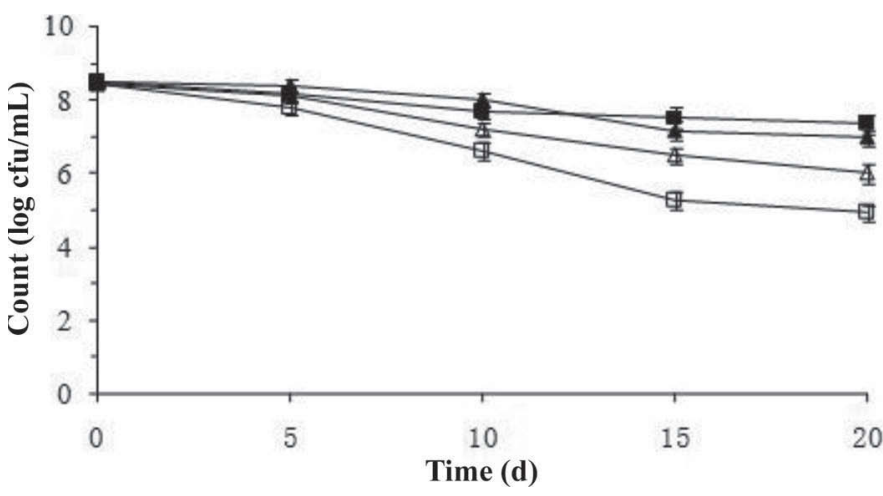

Figure 5. The curve of stationary phase cells to cold. Lactobacillus bulgaricus $(\Delta, \boldsymbol{\Delta})$ and its mutant $(\square, \boldsymbol{\square})$ were grown in de Man, Rogosa, Sharpe (MRS) broth at controlled temperature $\left(37^{\circ} \mathrm{C}\right)$ with no air (open symbols) or air sparging (closed symbols). Number of survivors was enumerated on MRS. Average of 3 replicates for a single fermentation with standard deviation bars. 
large number of genes, and the transcription levels of 2 stress-related proteins, Asp1 and Asp2, increased with the addition of $\mathrm{H}_{2} \mathrm{O}_{2}$ (Serrano et al., 2007).

In our experimental strategy, the temperature of sample adjusted to $4^{\circ} \mathrm{C}$ (close to the minimum temperature for growth for L. bulgaricus) and storage in a nutrientdepleted buffer is a cold stress condition. Starvation and temperature downshift are key factors that cause physiological changes of bacteria in viable but abnormal growth status (Keer and Birch, 2003). Survival during cold is usually attributed to the capacity of maintaining an active metabolic state and of avoiding energy depletion (Van de Guchte et al., 2002). The higher survival of cells may be due to a generalized stress response and to lower initial metabolic activity, whereas survival of aerobically grown exponential phase cells is higher, and at least after $15 \mathrm{~d}$ may be due to higher oxidative stress tolerance (Gaudu et al., 2002). Although CcpA regulates some key gene expression in carbon and nitrogen metabolism in gram-positive bacteria, it is different between these strains and other LAB reported on the roles of CcpA. Lactobacillus plantarum cells grown in aerobiosis were significantly less tolerant than mutant cells grown in the same conditions (Zotta et al., 2012), whereas the difference in survival for aerobic grown cells was negligible for both strains in this study. This study found that enzyme activities (LDH, PK, PFK) were significantly lower in aerobiosis than anaerobiosis for the wild type, but it was not significant for the mutant strain, which implies that CcpA may participate in cellular respiration.

\section{CONCLUSIONS}

The lower activities in the mutant strain correlate with decreased gene expression. After CcpA gene deletion, enzyme activities (LDH, PK, PFK) were significantly lower, which resulted in reduction of the glycolytic pathway, and caused reduction of the utilization ratio of glucose and decrease of growth rate. It is known that aerobic growth promote the presence of a respiratory chain, which is related to stress tolerance of some important LAB in the food industry. In our study, results showed that aerobic growth can significantly enhance heat and oxidative stress tolerance of L. bulgaricus. Furthermore, our team confirmed the role of the pleiotropic regulator CcpA in stress resistance and aerobic metabolism of L . bulgaricus. Some stress response proteins (DnaK, GroEL, GrpE, ClpL, $\mathrm{ClpE}$ ), detoxification of reactive oxygen species (Pox, Nox, Npr), and some other oxidoreductases or proteins related to stress (Hsp1, Asp1, Asp2) were affected by aerobic and anaerobic growth and by CcpA inactivation. Further work is needed to find these proteins in $L$. bulgaricus and clarify the regulation of the expression and their role in stress response.

\section{ACKNOWLEDGMENTS}

This work was supported by the National Natural Science Foundation of China (Grant No. 31201397, 31301519) and the Open Research Fund for Key Laboratory of Dairy Science, Ministry of Education in China (2012KLDSOF-06).

\section{REFERENCES}

Asanuma, N., T. Yoshii, and T. Hino. 2004. Molecular characterization of CcpA and involvement of this protein in transcriptional regulation of lactate dehydrogenase and pyruvate formate-lyase in the ruminal bacterium Streptococcus bovis. Appl. Environ. Microbiol. 70:5244-5251

Castaldo, C., R. A. Siciliano, L. Muscariello, R. Marasco, and M. Sacco. 2006. CcpA affects expression of the groESL and dnaK operons in Lactobacillus plantarum. Microb. Cell Fact. 5:35.

Esteban, C. D., K. Mahr, V. Monedero, W. Hillen, G. Pérez-Martínez, and F. Titgemeyer. 2004. Complementation of a $\Delta$ ccpA mutant of Lactobacillus casei with CcpA mutants affected in the DNA-and cofactor-binding domains. Microbiology 150:613-620.

Gaudu, P., G. Lamberet, S. Poncet, and A. Gruss. 2003. CcpA regulation of aerobic and respiration growth in Lactococcus lactis. Mol. Microbiol. 50:183-192.

Gaudu, P., K. Vido, B. Cesselin, S. Kulakauskas, J. Tremblay, L. Rezaiki, G. Lamberet, S. Sourice, P. Duwat, and A. Gruss. 2002. Respiration capacity and consequences in Lactococcus lactis. Antonie Van Leeuwenhoek 82:263-269.

Goffin, P., L. Muscariello, F. Lorquet, A. Stukkens, D. Prozzi, M. Kleerebezem, M. Sacco, and P. Hols. 2006. Involvement of pyruvate oxidase activity and acetate production in the survival of Lactobacillus plantarum during the stationary phase of aerobic growth. Appl. Environ. Microbiol. 72:7933-7940.

Gosalbes, M. J., V. Monedero, and G. Pérez-Martínez. 1999. Elements involved in catabolite repression and substrate induction of the lactose operon in Lactobacillus casei. J. Bacteriol. 181:3928-3934.

Keer, J. T., and L. Birch. 2003. Molecular methods for the assessment of bacterial viability. J. Microbiol. Methods 53:175-183.

Lechardeur, D., B. Cesselin, A. Fernandez, G. Lamberet, C. Garrigues, M. Pedersen, P. Gaudu, and A. Gruss. 2011. Using heme as an energy boost for lactic acid bacteria. Curr. Opin. Biotechnol. $22: 143-149$.

Lopez de Felipe, F., and P. Gaudu. 2009. Multiple control of the acetate pathway in Lactococcus lactis under aeration by catabolite repression and metabolites. Appl. Microbiol. Biotechnol. 82:11151122 .

Lorquet, F., P. Goffin, L. Muscariello, J. B. Baudry, V. Ladero, M. Kleerebezem, M. Sacco, and P. Hols. 2004. Characterization and functional analysis of the poxB gene, which encodes pyruvate oxidase in Lactobacillus plantarum. J. Bacteriol. 186:3749-3759.

Ludwig, H., G. Homuth, M. Schmalisch, F. M. Dyka, M. Hecker, and J. Stülke. 2001. Transcription of glycolytic genes and operons in Bacillus subtilis evidence for the presence of multiple levels of control of the gapA operon. Mol. Microbiol. 41:409-422.

Luesink, E. J., R. E. Van Herpen, B. P. Grossiord, O. P. Kuipers, and W. M. De Vos. 1998. Transcriptional activation of the glycolytic las operon and catabolite repression of the gal operon in Lactococcus lactis are mediated by the catabolite control protein CcpA. Mol. Microbiol. 30:789-798.

Magasanik, B. 1961. Catabolite repression. Cold Spring Harbor Symposia on Quantitative Biology. Cold Spring Harbor Laboratory Press, New York, NY. 26:249-256. 
Mahr, K., W. Hillen, and F. Titgemeyer. 2000. Carbon catabolite repression in Lactobacillus pentosus. analysis of the CcpA region. Appl. Environ. Microbiol. 66:277-283.

Mazzeo, M. F., G. Cacace, A. Peluso, T. Zotta, L. Muscariello, V. Vastano, E. Parente, and R. A. Siciliano. 2012. Effect of inactivation of CcpA and aerobic growth in Lactobacillus plantarum. A proteomic perspective. J. Proteomics 75:4050-4061.

Morel, F., M. Lamarque, I. Bissardon, D. Atlan, and A. Galinier. 2001. Autoregulation of the biosynthesis of the CcpA-like protein, PepR1, in Lactobacillus delbrueckii subsp bulgaricus. J. Mol. Microbiol. Biotechnol. 3:63-66.

Murphy, M. G., and S. Condon. 1984a. Correlation of oxygen utilization and hydrogen peroxide accumulation with oxygen induced enzymes in Lactobacillus plantarum cultures. Arch. Microbiol. 138:44-48.

Murphy, M. G., and S. Condon. 1984b. Comparison of aerobic and anaerobic growth of Lactobacillus plantarum in a glucose medium. Arch. Microbiol. 138:49-53.

Muscariello, L., R. Marasco, M. De Felice, and M. Sacco. 2001. The functional CcpA gene is required for carbon catabolite repression in Lactobacillus plantarum. Appl. Environ. Microbiol. 67:2903-2907.

Quatravaux, S., F. Remize, E. Bryckaert, D. Colavizza, and J. Guzzo. 2006. Examination of Lactobacillus plantarum lactate metabolism side effects in relation to the modulation of aeration parameters. J. Appl. Microbiol. 101:903-912.

Ramos, A., A. R. Neves, R. Ventura, C. Maycock, P. Lopez, and H. Santos. 2004. Effect of pyruvate kinase overproduction on glucose metabolism of Lactococcus lactis. Microbiology 150:1103-1111.

Rud, I., K. Naterstad, R. S. Bongers, D. Molenaar, M. Kleerebezem, and L. Axelsson. 2011. Functional analysis of the role of CggR (central glycolytic gene regulator) in Lactobacillus plantarum by transcriptome analysis. Microb. Biotechnol. 4:345-356.
Sánchez, B., L. Noriega, P. Ruas-Madiedo, C. G. Reyes-Gavilán, and A. Margolles. 2004. Acquired resistance to bile increases fructose6-phosphate phosphoketolase activity in Bifidobacterium. FEMS Microbiol. Lett. 235:35-41.

Schick, J., B. Weber, J. R. Klein, and B. Henrich. 1999. PepR1, a CcpA-like transcription regulator of Lactobacillus delbrueckii ssp. lactis. Microbiology 145:3147-3154.

Serrano, L. M., D. Molenaar, M. Wels, B. Teusink, P. A. Bron, W. M. De Vos, and E. J. Smid. 2007. Thioredoxin reductase is a key factor in the oxidative stress response of Lactobacillus plantarum WCFS1. Microb. Cell Fact. 6:29.

Titgemeyer, F., and W. Hillen. 2002. Global control of sugar metabolism: A gram-positive solution. Antonie Van Leeuwenhoek 82:5971.

Van de Guchte, M., P. Serror, C. Chervaux, T. Smokvina, S. D. Ehrlich, and E. Maguin. 2002. Stress responses in lactic acid bacteria. Antonie Van Leeuwenhoek 82:187-216.

van Kranenburg, R., J. D. Marugg, I. I. Van Swam, N. J. Willem, and W. M. De Vos. 1997. Molecular characterization of the plasmidencoded eps gene cluster essential for exopolysaccharide biosynthesis in Lactococcus lactis. Mol. Microbiol. 24:387-397.

Weickert. M. J., and S. Adhya. 1992. A family of bacterial regulators homologous to Gal and Lac repressors. J. Biol. Chem. 267:15869 15874.

Zomer, A. L., G. Buist, R. Larsen, J. Kok, and O. P. Kuipers. 2007. Time-resolved determination of the CcpA regulon of Lactococcus lactis ssp. cremoris MG1363. J. Bacteriol. 189:1366-1381.

Zotta, T., A. Ricciardi, A. Guidone, M. Sacco, L. Muscariello, M. F. Mazzeo, G. Cacace, and E. Parente. 2012. Inactivation of CcpA and aeration affect growth, metabolite production and stress tolerance in Lactobacillus plantarum WCFS1. Int. J. Food Microbiol. 155:51-59. 